\title{
Research on Advance of Rice False Smut Ustilaginoidea virens (Cooke) Takah Worldwide: III. Infection Cycle and Invasion Mechanism of $U$. virens and Rice Resistance to RFS
}

\author{
Shiwen Huang ${ }^{1,2}$, Lianmeng Liu ${ }^{1,3}$, Ling Wang ${ }^{1} \&$ Yuxuan Hou ${ }^{1}$ \\ ${ }^{1}$ State Key Laboratory of Rice Biology, China National Rice Research Institute, Hangzhou, China \\ ${ }^{2}$ Agricultural College, Guangxi University, Nanning, China \\ ${ }^{3}$ College of Plant Science and Technology, Huazhong Agricultural University, Wuhan, China \\ Correspondence: Shiwen Huang, State Key Laboratory of Rice Biology, China National Rice Research Institute, \\ Hangzhou 311401, Zhejiang, China. Tel: 86-133-8860-8130. E-mail: huangshiwen@caas.cn
}

Received: July 6,2019 Accepted: August 9, $2019 \quad$ Online Published: September 15, 2019

doi:10.5539/jas.v11n15p263 URL: https://doi.org/10.5539/jas.v11n15p263

The research is financed by China-Norway international cooperation project: "CHN-2152, 14-0039 SINOGRAIN project II"; The key $R$ \& D project of Zhejiang province (2019C02018); Innovation project of CAAS (CAAS-ASTIP-2013-CNRRI); The National Key $R$ \& D Projects of China (2018YFD0200304, 2016YFD0200801); Shanghai municipality project: "Agriculture through science and technology" (2019-02-08-00-08-F01127).

\begin{abstract}
In this part, the infection cycle and invasion mechanism of RFS, including the primary and secondary source of RFS infection. The factors affecting the disease occurrence and epidemiology, including the infection time and pathway, different conditions affecting the incidence of RFS, for example, the type of rice varieties and morphological characteristic, meteorological factors, environmental conditions, cultivation management, and amount of $U$. virens in the field. The mechanism of rice varieties' resistance to RFS were also discussed, including morphological characteristics, and biochemical mechanism, resistance genes of rice.
\end{abstract}

Keywords: $U$. virens, Infection cycle and mechanism, affect factors, rice resistance and mechanism

\section{Introduction}

To understand the invasion mechanism and cycle of $U$ virens, the resistance and the resistant mechanism of rice varieties to RFS, there are significance for further study of $U$. virens and effective prevention and control of RFS, as well as rice genetic breeding for disease resistance. There are different viewpoints on the source of infection in the early, but a more consistent view was that the overwintering sclerotia and chlamydospore are the main original resources of infection. There are many factors affect the occurrence and prevalence, for example, the climate conditions, temperature, humidity, hours of illumination, especially the "key growth stage of rice" (KGSR, i.e., the late booting stage and begin heading to flowering period are the susceptible period of rice to RFS) encounter the local climatic conditions which suitable for the occurrence of RFS; The resistance of rice to RFS, fertilizer and water management, and amount of original $U$. virens. The mechanism of rice varieties' resistance to RFS was determined by itself genetic, for example, the morphological characteristics of rice variety, the content and activity of biochemical substances. However, the most essential factors are the resistance genes of rice varieties.

\section{Disease Cycle of RFS and Factors Affecting the Disease Occurrence}

Knowledge of the pathogen's life history and infection process in nature is critical for disease control (Tang et al., 2012b). 


\subsection{Primary Infection Source of RFS}

$U$. virens can overwintering in the form of mycelium, chlamydospore, sclerotium and RFS balls. The overwintering sclerotia germinated and produced ascospores, which caused rice false smut in the coming year (Liao, 1994). Inoculation with chlamydospore, ascospores and thin-wall conidia can successfully induce RFS (Chen et al., 1995; Huang et al., 2002; Yao et al., 2012). Zuo et al. (1996) captured chlamydospores over the rice fields, suggesting that chlamydospores have the ability of air flow spreading. Therefore, it is deduced that there is a pathogen source base or intermediate host suitable for the dormancy of chlamydospore outside rice fields. However, there is a totally different point of view on this point. Chen et al. (1994c) believed that chlamydospores in soil germinated and produced conidia, and the conidia spreading by wind and rain and caused the primary infection; However, the sclerotia were not found in some areas of some provinces in China, but the rice was infected by $U$. virens every year, so it was really questionable that sclerotium was the major primary infection source (Wang, 1992; Chen et al., 1995). On the other hands, Liu et al. (2009b) demonstrated that the primary infection source of RFS mainly was the seeds with pathogen, followed by the overwintering pathogen in soil.

Most scholars abroad were consistent with the views that the pathogens overwintering in the form of sclerotium and chlamydospore were the major primary infection sources, and the chlamydospores played a decisive role in the secondary infection (Ikegami, 1963; Ou, 1985).

\subsection{Secondary Source of RFS Infection}

A more consistent view on the secondary infection source of false smut is chlamydospores. The chlamydospores in soil germinated and produced conidia, and the conidia caused primary infection by spreading through wind and rain. Many studies have reported that there was a severe incidence of RFS in late maturing varieties, and that the secondary infection may be the major factor (Chen et al., 1994c). A large number of chlamydospores could be captured over the rice field, and the number of spores was relatively increased with the arrival of the flowering period. Evidently, the secondary infection source of RFS is mainly chlamydospores and conidia by air spread (Ou, 1985).

\subsection{Infection Time and Pathway}

The infection periods and pathways of $U$. virens are not very clear. There are main views of the seedling stage system infection, or late booting to early heading stage infection (late stage infection), or systemic infection and late growing stage infection. However, more advanced inoculation and detection technology have been employed recently, indicating that RFS infection is mainly in the late stages.

\subsubsection{Systematic Infection in Seedling Stage}

The experimental results demonstrated that the infection of $U$. virens may be the seedling stage systematic infection. When rice seeds with pathogen germination, the pathogenic spores can successfully infect a large number of radicles and coleoptiles, and extend along the outer surface of the sieve tube of the phloem until reaching the middle and late stages of tillering (Ikegami, 1962, 1963; Schroud et al., 2005). It was subsequently found by histological observation and molecular techniques detected that the pathogen can attack the root at the seedling stage and lead to symptomless colonization of the entire plant (Ditmore et al., 2006; TeBeest, 2010). Dai et al. (2005) detected and found that the conidia of $U$. virens formed mycelium on the surface of the glume and extended into the inner hull, which provides evidence for the direct infection of conidia on rice grains.

A large number of comparative field studies regarding to whether the rice seeds with pathogen can lead to occurrence of RFS have conducted. Some results indicated that seeds with pathogens can cause RFS (Chen et al., 1994b; Liu et al., 2009b). Overwintered chlamydospores could infect seeds, seedling coleoptiles, leaves and roots of the early rice, and cause RFS during heading stage (Chen et al., 1995; Gao et al., 2011). Rice seeds contaminated by $U$. virens and treated with biocidal (pathogens-free) were sown and planted under sterile soil and isolated conditions, the rice seeds carrying pathogens could induce RFS, while the sterilized seeds could not induce diseases, indicating that the seeds could carry pathogens and caused RFS (Liao, 1993). By using spray or injection inoculation with chlamydospores at the rice seeds germination, seedling or booting stages, it could successful caused RFS (Ikegami, 1962, 1963; Miao, 1992).

\subsubsection{Late Growth Stage Infection}

Most researchers believed that the primary infection site was the floral organ of rice, and the infection period was between the middle and late booting stages to the early heading period (Xu et al., 2001; Wang et al., 2008; Chen et al., 2013). Liu et al. (2007) believed that the main infection period of $U$. virens was between the big belly stage to begin heading period, but not the seed germination stages. Strong evidences support that the infection occurred in flowering stage was that artificial inoculation in the late booting stage could increase the 
diseased panicle rate substantially (Cai et al., 2009; Gao et al., 2011). At present, it was believed that 1-2 weeks before heading are the main invasion period of RFS (Li et al., 1986; Wang, 1992; Guo et al., 2000). Du et al. (1990) illustrated that seed treated with biocidal there was no effect of prevention and cure RFS, and inoculation with $U$. virens after germination of rice seeds also did not incur the disease, proving that $U$. virens is not systemic infection.

An experiment of bagging protection was conducted, the results have shown that there was no occurrence of RFS when rice plants were bagged in elongation stage and early booting stage, while RFS occurred in all of the treatments of bagging after the late booting stage (pollen mother cells (PMC) filling stage), indicating that the infection of RFS began early booting and late booting stage (Deng et al., 1990) (Table 1).

Table 1. Studies on the infection stage of RFS by bagging

\begin{tabular}{|c|c|c|c|c|c|}
\hline Treatment & $\begin{array}{l}\text { Rate of } \\
\text { infected } \\
\text { panicle } \%\end{array}$ & $\begin{array}{l}\text { Rate of } \\
\text { diseased } \\
\text { grain\%o }\end{array}$ & Treatment & $\begin{array}{l}\text { Rate of } \\
\text { infected } \\
\text { panicle } \%\end{array}$ & $\begin{array}{l}\text { Rate of } \\
\text { diseased } \\
\text { grain\%o }\end{array}$ \\
\hline Bagging at elongation stage & 0 & 0 & Inoculation at elongation stage & 0 & 0 \\
\hline Bagging at early booting stage & 0 & 0 & Inoculation at early booting stage & 0 & 0 \\
\hline Bagging at late booting stage & 15.0 & 5.68 & Inoculation at late booting stage & 38.6 & 17.8 \\
\hline Bagging at begin heading stage & 9.5 & 3.86 & Inoculation at begin heading stage & 18.5 & 8.24 \\
\hline Bagging at full heading stage & 5.2 & 1.12 & Inoculation at full heading stage & 5.2 & 3.36 \\
\hline
\end{tabular}

From the incidences of RFS of different period inoculation with $U$. virens, there was no RFS occurred during the elongation stage and the meiosis stage of PMC, while most serious occurred of RFS with inoculation during late booting stage and begin heading stage. Inoculation at begin heading and full heading stages of rice, there were a small amount of RFS balls appeared, suggesting that the infection of RFS mainly occurred after late booting stage (Hu et al., 2010; Liu et al., 2009b). The inoculation was performed at 6 to $9 \mathrm{~d}$ before heading, then the incidence were the highest either for resistant or susceptible rice varieties; in addition, the incidence was very low or there was no occurrence of RFS for the inoculation at 10 to $13 \mathrm{~d}$ before heading (Zhang et al., 2004).

Field observations and the results of inoculation experiments combined with histological studies, now suggest that the most likely route of $U$. virens infection is when rice plants are at the booting stage (Sonoda et al., 1997; Ashizawa et al., 2012). Furthermore, experiments using a mixture of conidia and hyphae of $U$. virens cultured demonstrated that serious cases of RFS could arise when the inoculation was made by injecting the panicles at the booting stage (Zhang et al., 2004; Sonoda et al., 1997; Ashizawa et al., 2011).

\subsubsection{Systematic Infection + Late Stage Infection}

There were also experiments supporting that RFS not only could infect systematically, but also infect at late stage (Liao, 1992). Artificial inoculation with chlamydospores at early and middle seedling stages of rice, it could induce RFS at adult periods. After three years and nine experiment replicates, it was proven that the $U$. virens could infect rice most easily from the formation of young panicle to the middle of the booting stage, and the rice was basically not be infected after begin heading (Chen et al., 1994a).

\subsubsection{Infection Site and Infection Mechanism of $U$. virens}

A recent cytological study indicated that the pathogen of $U$. virens infected the filaments intercellular and extended intercellular along the filament base (Tang et al., 2012b). It was found that the hyphae of $U$. virens are able to invade the spikelet apices, via a small gap between the lemma and palea.

Infection sites: Examination of serial semi-thin and ultrathin sections of infected spikelets showed that the primary infection sites of $U$. virens was upper parts of the three stamen filaments located between the ovary and the lodicules. The pathogen did not penetrate host cell walls directly and did not form typical appressoria structures and haustorium. The ovary remained alive in the RFS ball and was never infected (Tang et al., 2012b). $U$. virens did not kill the host cells, so it belongs to living nutrition type fungus (Hu et al., 2012a; Tang et al., 2012b).

In the booting stage, $U$. virens specifically infects the stamen filaments of rice, and thus it grows and develops into chlamydospores and finally formed smut ball. $U$. virens could not infect the ovary and anther, however, the secondary hyphae can occasionally infect the stigma and outer cells of lodicule (Dai et al., 2005). However, 
Dodan et al. (1996) and Mandhare et al. (2008) found that conidiophore of $U$. virens could infect the ovary and single spikelet and then transformed into chlamydospores and false smut ball.

A recent study has indicated that $U$. virens follows a specific route, with the hyphae colonizing the outer surface of the spikelet, and then entering the inside of spikelet from the apex (Ashizawa et al., 2012). Consistent with a previous report (Tang et al., 2012b), U. virens initially attaches itself to the surface of the filaments, and then formed several discrete structures, including mycelial stroma and infection hyphae.

Mechanism of infection: The route of $U$. virens penetrates rice panicles has long been a question of debate. A recent study utilized a transgenic strain expressing green fluorescent protein gene (GFP) (Ashizawa et al., 2012) to observe the $U$. virens' initial infection of rice panicles before heading. The detection method of nested PCR to detect the $U$. virens, and found that there were attachment and infection in the early reproduction stage of rice (Zhou et al., 2003, 2006; Wang et al., 2005a). The GFP-labeled conidia of U. virens were injected into rice sheaths at booting stage, there were a lot of conidia present on spikelet surfaces 48 hour post-inoculation (hpi), hyphae had invaded spikelets through the apices, via the small gap between the lemma and palea and had already reached all floral organs 144 hpi (Ashizawa et al., 2012).

The primary site of $U$. virens colonization was at the base of the filaments with the inner spikelets becoming infected by hyphae at 24 hpi. The accumulation of hyphae reached its highest level at $168 \mathrm{hpi}$, before rice heading stage, as the infection extended upward from basal filaments to the anther apex, and then enclosed all the floral organs to produce a velvety smut ball (Hu et al., 2014).

\subsection{Conditions Affecting the Incidence of RFS}

The occurrence and epidemic of RFS was affected by many factors, for example, the amount of $U$. virens and its pathogenicity, resistance of rice varieties, climate factors, and cultivation management. The susceptible varieties and continuous rainfall for more than $5 \mathrm{~d}$ during rice booting and heading period are the two key factors to cause outbreak and epidemiology of RFS (Hu et al., 2010). Rice plants at late booting stage, and flowering to filling stage encounter a relatively low temperature (i.e., $22-28^{\circ} \mathrm{C}$ ), rainy and humid climate or rainy weather exceed consecutive $5 \mathrm{~d}$ days, the degree of RFS incidence will be serious (Wang et al., 2005b; Liu et al., 2000).

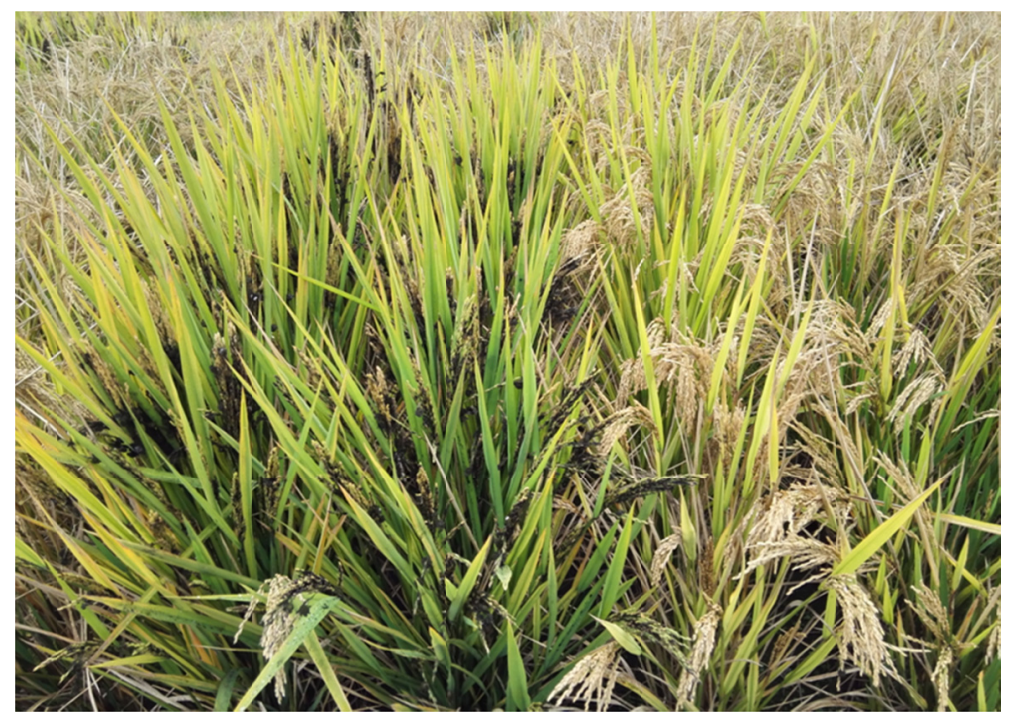

Figure 1. Late maturing variety (left) was seriously infect by RFS but early maturing (right) no any infection

\subsubsection{Resistance of Rice Varieties}

The resistance difference of different rice varieties to RFS varies greatly (Chen et al., 1992, 1994c). Observation in the paddy fields combined with artificial inoculation in greenhouse and field natural infection have both proven that there was real resistance to RFS of different rice varieties (Ashizawa et al., 2011; Tang et al, 2012a). Under natural conditions, the infected panicle rate and the disease index of different varieties vary greatly, and the values were in the ranges of $0.43-33.04 \%$ and $0.05-16.14 \%$, respectively (Jin et al., 2005; Lu et al., 2008). The resistances of rice varieties were affected by the internal genetic mechanism (Xu et al., 2002; Fang et al., 2008) and external morphological characteristics. 
Rice varieties types: The resistance difference of rice varieties has close relationships to types of rice varieties, plant types, and growth characteristics. In general, the waxy type varieties are more susceptible to RFS than that of the japonica varieties, and the japonica is more susceptible than indica varieties. Erect dense panicle varieties are more susceptible to RFS than that of general varieties, the incidence of RFS in hybrid rice was much more severe than that of the conventional rice varieties (Wang et al., 2004; Lv et al., 2007). The short-stalked, large panicle, wide leaf but small angle varieties are fertilizer tolerant and lodging-resistant, and they are suitable for high density planting, which are in favor of the occurrence of RFS. Varieties with long duration of tillering, booting and flowering stage, the incidence of RFS is also more serious. The RFS in the two-line hybrid rice was more serious than that of the three-line hybrid rice (Liu et al., 2009a; Tang et al., 2012a; Gan et al., 2013).

Rice plants morphology: The effects of rice plant types on the occurrence of RFS vary greatly (Hu et al., 2012b). The occurrence of RFS has a close relationship to the panicle traits, and the correlations are as follows: grain number per panicle $>$ secondary branch grain number $>$ secondary branch number $>$ the seed density. The number of grains per panicle, especially the number of grains in the secondary branch, is the main causes of the high incidence of RFS (Wang et al., 2004).

\subsubsection{Meteorological Factors: Temperature, Rainy Days and Rainfall, Humidity, Light, etc.}

It was demonstrated with many years observation in the fields, the RFS incidence of the same rice variety in different years are quite different. If the resistant varieties of rice encounter rainy days during the booting period and begin heading stage, then the incidence of RFS will be aggravate; on the contrary, if the susceptible varieties encounter dryness and high temperature weather during these stages, then the incidence of RFS will decrease or even no be infected (Wang et al., 2004).

The climate factor that rice plants encounter in vulnerable period or KGSR is one of the key factors determining the degree of RFS incidence. If KGSR encounter more rainy days, abundant rainfall, a short sunshine duration, the relative humidity (RH) was high (above $85 \%$ ), the temperature was suitable $\left(22-28{ }^{\circ} \mathrm{C}\right.$ ), and a small temperature difference between day and night, then the degree of RFS incidence was severe. If these factors were contrary, then the degree of RFS incidence was low (Yashoda et al., 2000; Ye et al., 2005; Yang, 2007; Fei et al., 2010). It was found that the severity of RFS was closely related to the local accumulated sunshine hours and total rainfall in KGSR. If the number of sunshine hours was reduced and the rainfall was increased, then the morbidity of RFS was aggravated (Pan et al., 1997b).

The rain days and rainfall during the KGSR were positively correlated with the infected panicle rate, the correlation coefficient was $r=0.8342^{*}$ and $r=0.8826^{*}$, and the related equation was $Y=-6.7985+6.0538 x$ and $\mathrm{Y}=-2.6963+0.3652 \mathrm{x}$, respectively. RFS is negatively correlated with the daily mean temperature but positive correlated with humidity at the begin heading stage. When the daily mean temperature was $23-24{ }^{\circ} \mathrm{C}$ and $\mathrm{RH}$ $82 \%-87 \%$ during the begin heading period are conducive to the occurrence of RFS (Lv et al., 2007).

Shading and RFS: Rice plants were treated with two or three layers of gauze for shading, the number of infected hills, panicles and grains by RFS are 1.08-1.37, 1.19-1.66 and 2.53-3.94 times of those no-shading controls, respectively (Qian et al., 1993). The experimental results verified that cloudy and rainy weather was conducive to the occurrence of RFS (Table 1).

\subsubsection{Environmental Conditions}

The RFS incidences of the same rice varieties in the same year which planted in different areas are different. Occurrences of RFS are associated with altitude and ecological environment, and the incidence of high altitude was more severe than that of the low altitude; the incidence of RFS in temperate and highlands is low, while in tropical lowlands is high (Zhang et al., 2006a). Even in the same paddy field, the rice plants incidence of RFS on the edge was severe, while in the middle of the field was low (Jin et al., 2005; Chen et al., 2005).

\subsubsection{Cultivation Management}

The occurrence of RFS is also associated with rice cultivation and management, especially the management of fertilizer and water.

Fertilization: Different fertilizer, dosage of application and application time of fertilizer significantly affect the occurrence and severity of RFS. The incidence of RFS was higher if more nitrogen fertilizer was applied and the application time was late (Bhardwaj, 1990; Pan et al., 1993; Ye et al., 2005; Yang, 2007). Increasing the amount of nitrogen fertilizer significantly increased the rate of infected rice plants.

Fertilization habit of partial nitrogen, excess dosage of fertilizer and late fertilization will reduce the rice resistance ability to RFS (Zhao, 2008). The applied total quantity of nitrogen $\left(\mathrm{X}_{1}\right)$, amount of panicle fertilizer 
$\left(\mathrm{X}_{2}\right)$ and application time of panicle fertilizer $\left(\mathrm{X}_{3}\right)$ were strongly affect the incidence of RFS (Y), the regression equation was $\mathrm{Y}=-93.053+3.393 \mathrm{X}_{1}+9.265 \mathrm{X}_{2}+3.711 \mathrm{X}_{3}$, and the correlation coefficient $\mathrm{R}=0.8922^{* *}$. Among all of these factors, the direct effect of the application amount of ammonia fertilizer on the RFS incidence was the highest, $\mathrm{P}_{0.1}=0.393$ (Pan et al., 1997a). If $600 \mathrm{~kg} / \mathrm{hectare}$ of urea was used as panicle fertilizer, then the infected panicle rate was $17.5 \%$, and increased by $34.6 \%$ and $48.9 \%$ compared with that of the $300 \mathrm{~kg} / \mathrm{hectare}$ and no application of the panicle fertilizer (Chen et al., 2009a).

When 165.0, 225.0, 232.5, 240.0 and $300.0 \mathrm{~kg}$ of pure $\mathrm{N}$ was used as the topdressing fertilizer (urea) per hectare at heading period, the infected rice panicle rates of RFS were $1.33 \%, 1.97 \%, 2.13 \%, 2.33 \%$ and $3.13 \%$ (Chen et al., 2000), respectively. Reasonable amounts ratio of nitrogen, phosphorus and potassium fertilizer were beneficial to increasing rice yield and reducing the occurrence and harm degree of RFS (Wang et al., 2010; Hong et al., 2013; Qing et al., 2014).

Transplanting method and water management: The planting density and water management also affect the incidence of RFS. Close planting and long-term deep water irrigation can increase the incidence of RFS. Waterlogging paddy fields, especially long-term waterlogging in late stage of rice growing will lead to high humidity and result in serious occurrence of RFS (Zhang et al., 1997; Zhang et al., 2005; Yang, 2007; Wang et al., 2010).

Sowing and transplanting period. Generally speaking, the incidence of RFS of early transplanting rice groups were significantly lower than those of the late transplanting for each rice variety in the same area (Wang et al., 2010). The infected rate of the late maturing group and early maturing group varieties were investigated in 2005 and 2006, the infected rate of hill, panicle and grain were $76.3 \%, 26.6 \%, 4.6 \%$ and $16.8 \%, 5.4 \%, 4.7 \%$ for the same rice variety, respectively (Lu et al., 2006).

The sowing and transplanting time of rice will determine the time of KGSR, and affects the KGSR if encounter the local climatic conditions which suitable for the occurrence of RFS. It was reported that the reason for the severe incidence of RFS was that the heading stage met the most appropriate of the local meteorological conditions for the occurrence of RFS (Singh et al., 1981). The incidence rate of RFS of the early sowing was only $0-3.1 \%$, while for the late sowing rice it was $48.5-56.1 \%$ (Ahonsi et al., 2000).

\subsubsection{Amount of $U$. virens in the Field}

The occurrence of RFS was positively correlated with the accumulation degree of $U$. virens in the fields. In general, the occurrence of RFS in the old disease areas and/or used to be serious occur areas then the RFS is high, due to the large number of $U$. virens left behind previous year was significantly higher than that of the field with little pathogen, and vice versa (Liao, 1994; Zhou et al., 2010).

\section{Rice Resistance to RFS and Their Mechanism}

Most researches did not find any rice varieties (materials) with immunity or high resistance to RFS (Guo et al., 2010; Jiang et al., 2010a, 2010b; Zheng et al., 2013), but there were some studies which found highly resistant and immune varieties (Huang et al., 2010). It was verified by natural infection or artificial inoculation that there were significant differences in resistance to RFS among rice varieties (Yang et al., 2008). Many research results and long-term field observation have both shown that the resistance of rice varieties to RFS was real subsistent. 198 rice varieties were identified by using artificial injection inoculation method of the conidia suspension liquid, there were 44 rice varieties with complete immunity to RFS, 34 varieties with high resistance (Chen et al., 2009b). The identification results of Pan et al. (2012) showed that the resistance of rice varieties to RFS were actual existence, for example, the most serious infected panicle rate reached up to $80 \%-90 \%$ of the susceptible rice variety, while for the resistant one, there was low infected panicle rate (Singh et al., 1987; Phatak et al., 1991; Lore et al., 2013). The incidence of 160 rice varieties were investigated under natural conditions, and demonstrated that there were 16 varieties with resistance (Urmila et al., 1999).

\subsection{Morphological Characteristics and Rice Resistance to RFS}

There are also differences in the resistances to RFS of rice varieties with different morphological characteristics (Hu et al., 2012b). RFS incidence was closely related to panicle traits, the following order affect the RFS severity from large to small, secondary branch number $>$ secondary branch grain number $>$ grain number per panicle > grain density. Grain density was the main factor affecting the incidence of RFS (Xu et al., 1987). The incidence was significantly and positively correlated with the flag leaf width, and extremely significantly negatively correlated with the number of panicles per unit area, flag leaf angle and plant height. The more number of grain per panicle was, the higher incidence of RFS. Large-panicle type, more grain numbers and high grain density of rice cultivars were more easily to be infected by RFS (Chen et al., 2011). 


\subsection{Biochemical Mechanism and Rice Resistance to RFS}

The glume of resistance varieties had large amounts of lignin, while the susceptible varieties had less lignin; and the red fluorescent substances in the glume of the resistant cultivars were higher than those of the susceptible one. The endosperm cells of the resistance varieties had more polyphenols, but there was no polyphenols in the susceptible varieties (Dai et al., 2005). Rice plants were inoculated with conidia suspension of $U$. virens, the content of MDA was significantly increased in the susceptible varieties, and the content changes of resistant cultivars were smaller; the CAT activity of the resistant varieties was decreased, and that of the susceptible varieties was increased. The activities of POD, PAL and PPO of the resistant varieties increased, and the susceptible cultivars did not show significant changes when rice plants were inoculated with conidia suspension of $U$. virens; but the differences of SOD activity between the resistant and susceptible varieties were not significant (Jiang, 2010; Li et al., 2010). The activity of the CAT of the susceptible varieties decreased, while the PAL activity increased after inoculation (Lu, 2013). Gan et al. (2013) believed that there were no inevitable correlations between rice resistance and the activities of the defense enzymes POD and SOD. Brassinosteroids in rice plant may have more important roles than that of salicylic acid and ethylene in response to $U$. virens infection, the disturbance of other hormones such as auxin, gibberellins and jasmonates may also affect $U$. virens infection (Yang et al., 2014).

\subsection{Resistance Genes of Rice}

Hereditary resistance to RFS of rice was not only controlled by major gene, but also affected by multiple genes, which was consistent with the E-1-3 genetic model, namely two pairs of major genes plus the polygene mixed genetic model. The heritability of the major gene was $76.67 \%$, and the polygene was $22.86 \%$ (Li et al., 2008). The resistance of rice varieties to RFS was affected by additive and non-additive effects, and the effect of the female parent had a critical influence (Wang et al., 2013). The dynamic expressions of RFS progression- related protein genes including $O S P R 10 a$, OsPRla and $O S P R 1 b$ were analyzed by using RT-PCR. The expressions intensity of PRPG OsPR10a, OsPRIa and OSPRIb in incompatible interaction process were shown to be higher than those of the compatible interaction (Lu, 2013).

\subsection{The Genes Location of Rice Resistance to RFS and Their Distribution}

There were 146 molecular markers were selected from the recombinant inbred lines (RILs) of Lemont/Teqing. The total genetic distance of 146 markers was $2227.6 \mathrm{cM}$, covering $95.6 \%$ of the donor genomes, and the average adjacent marker distance was $15.2 \mathrm{cM}$. There were two anti-RFS of rice QTL ( $Q F s r 10$ and $Q F s r 12)$ were located on the $10^{\text {th }}$ and $12^{\text {th }}$ chromosomes, the enhanced resistance alleles were from the parent Lemont, and the respective additive effects were 3.38 and 3.34 (Xu et al., 2002). Quantitative resistance loci (QRL) was identified using 213 introgression lines (ILs) from a cross between Teqing (recipient) and Lemont (donor). Ten QRL affecting percentages of infected hills, panicles and spikelets were detected and mapped to rice chromosomes 2, 3, 4, 6, 8, 10, 11 and 12. Four QRL of qFSR-6-7, qFSR-10-5, qFSR-10-2 and qFSR-11-2 had relatively larger and consistent effects (Zhou et al., 2014).

Seven QTLs of $q F s r 1, q F s r 2, q F s r 4, q F s r 8, q F s r 10, q F s r 11$ and $q F s r 12$ were detected (Li et al., 2011), which were respectively located on the $1^{\text {st }}, 2^{\text {nd }}, 4^{\text {th }}, 8^{\text {th }}, 10^{\text {th }}, 11^{\text {th }}$ and $12^{\text {th }}$ chromosomes, and the contribution rate was 9.8\%-22.5\%. The explanation rate of the trait of $q F s r 10$ and $q F s r 11$ was between $18.0 \%-19.3 \%$ and the disease index of RFS was decreased by $8.0-16.3 \%$.

\section{Acknowledgments}

Authors are highly thankful to the projects for their kind support.

(1) China-Norway international cooperation project: "CHN-2152, 14-0039 SINOGRAIN project II";

(2) The key R \& D project of Zhejiang province (2019C02018);

(3) Innovation project of CAAS (CAAS-ASTIP-2013-CNRRI);

(4) The National Key R \& D Projects of China (2018YFD0200304, 2016YFD0200801);

(5) Shanghai municipality project: “Agriculture through science and technology" (2019-02-08-00-08-F01127).

\section{References}

Ashizawa, T., Takahashi, M., Arai, M., \& Arie, T. (2012). Rice false smut pathogen, Ustilaginoidea virens, invades through small gap at the apex of a rice spikelet before heading (Fungal diseases). J Gen Plant Pathol, 78, 255-259. https://doi.org/10.1007/s10327-012-0389-3 
Ashizawa, T., Takahashi, M., Moriwaki, J., \& Hirayae, K. (2011). A refined inoculation method to evaluate false smut resistance in rice. J Gen Plant Pathol (Fungal Diseases), 77, 10-16. https://doi.org/10.1007/ s10327-010-0279-5

Bhardwaj, C. L. (1990). False smut incidence on rice relative to plant characters and environmental factors. International Rice Research Newsletter, 15(3), 29-30.

Cai, H., \& Zhou, Y. (2009). Observation and detection of Ustilaginoidea virens in inoculated rice spikelets. $J$ of Fungal Res, 7(3-4), 164-166.

Chen, F., Lin, T., Gan, L., Du, Y., Ruan, H., \& Yang, X. (2013). SCAR marker and PCR detection of Ustilaginoidea viren. Acta Phytopathologica Sinica, 40(6), 481-487. https://doi.org/10.3724/SP.J.1206. 2013.00017

Chen, H. \& Yao, K. (2000). Preliminary report of effect on rice false smut of nitrogen fertiliser application. Jiangsu Agri Machinery and Agri Tech, 4, 15.

Chen, Y., \& Xiao, Y. (1995). The capacity of germination and infection of overwintered chlamydospores of Ustilaginoidea virens (Cooke) Tak. Acta Phytopathologica Sinica, 22(2), 102-106.

Chen, Y., Li, Y., Chen, Z., \& Wei, Z. (2011). Evaluation of rice resistance to false smut of regional trial varieties in Hunan province. Hunan Agri Sci, 11, 90-91.

Chen, Y., Xiao, Y., \& Zhao, Y. (1994a). Studies on the main period of false smut pathogen (Ustilaginoidea virens) invades rice. Hubei Agri Sci, 1, 24-26.

Chen, Y., Xiao, Y., \& Zhao, Y. (1994b). Studies on seeds transmit disease of rice false smut. Hubei Plant Protection, 3, 2-3.

Chen, Y., Zhou, Y., Liu, F., \& Jin, Z. (2005). Studies on rice false smut characteristics of distribution and effect factor to rice yield. Zhejiang Agri Sci, 4, 301-304. https://doi.org/10.1631/jzus.2005.B0301

Chen, Z., \& Chen, Y. (1994). Studies on infecting regularity and control technology of rice false smut. Technology and Extension of Plant Protection, 1, 8-9.

Chen, Z., Nie, Y., \& Liu, Y. (2009b). Identification of rice resistant to rice false smut and the virulence differentiation of Ustilaginoidea virens in Jangsu Province. Jiangsu J of Agri Sci, 25(4), 737-741.

Dai, G., Zhao, J., He, R., Jin, S., \& Nicole, M. (2005). Histochemical observation on the resistant and susceptible varieties to Ustilaginoidea virens (Cooke) Tak and the way of infection of conidia. Acta Phytopathologica Sinica, 35(1), 37-42.

Deng, G., \& Chen, J. (1990). Studies on the function of Ustilaginoidea virens chlamydospore in infection circulation. Chinese Agri Sci Bull, 6(2), 20-22.

Ditmore, M., Moore, J. W., \& TeBeest, D. O. (2006). Infection ofplants of selected dee cultivars by the false smut fungus, Ustilaginoidea virens, in Arkansas. In R. J. Norman, J. F. Meullenet, \& K. A. K. Moldenhauer (Eds.), Wells Rice Research Studies 2006. Arkansas Agricultural Experiment Station Research Series (Vol. 550, pp. 132-138).

Dodan, D. S., \& Singh, R. (1996). Recent advances in research on cowpea diseases. Present Status Agri Rev, 17(4), 227-240. https://doi.org/10.1016/S0273-1177(96)90668-7

Du, Y., Chu, M., Wang, S., Xu, H., Bai, Y., \& Shao, X. (1990). Preliminary research report on the rice false smut occurrence regularity and cultivation management. Liaoning Agri Sci, 6(2), 11-14.

Fei, Y., Chen, L., Yu, C., \& Chen, Z. (2010). Analysis on meteorological conditions in 2008 that caused heavy rice false smut in Chengdu Plain. J of Anhui Agri Sci, 38(8), 4108-4109.

Gan, L., Lin, T., Ruan, H., Du, Y., Shi, N., Chen, F., \& Yang, X. (2013). Study on breeding period characters of resistant and susceptible rice cultivars to false smut of rice. Chinese Agri Sci Bull, 29(36), 343-34.

Gao, B., \& Zhong, J. (2011). Research advances in infection processof Ustilaginoiden virens. Hunan Agri Sci, 3, 93-97. https://doi.org/10.4028/www.scientific.net/AMR.383-390.93

Guo, R., Wu, W., \& Xue, Q. (2000). Studies on the invasion stage of rice false smut pathogen (Ustilaginoidea virens). Plant Protection, 26(2), 25-26.

Guo, Y., \& Jiang, S. (2010). Evaluation of field resistance to false smut (Ustilaginoidea virens) of 30 rice varieties. Plants Doctor, 23(4), 32-34. 
Hong, S., Jiang, S., Xu, X., \& Huang, J. (2013). Effect on the occurrence of rice sheath blight and false smut of fertilizer operations. Jiangsu Agri Sci, 41(7), 127-128.

Hu, D., \& Wang, S. (2012a). Progress and perspectives in infection mechanism of Ustilaginoidea virens. Scientia Agricultura Sinica, 45(22), 4604-4611.

Hu, G., Pan, C., Pan, H., Zhu, G., \& Ding, X. (2010). Studies on the causes of rice false smut serious occurrence and key technology of chemicals control. Anhui Agri Sci Bul1, 16(5), 98-100.

Hu, M., Luo, L., Wang, S., Liu, Y., \& Li, J. (2014). Infection processes of Ustilaginoidea virens during artificial inoculation of rice panicles. Eur J Plant Pathol, 139, 67-77. https://doi.org/10.1007/s10658-013-0364-7

Hu, R., Ye, H., Yao, L., Gong, X., Lu, D., Mao, J., \& Liu, J. (2012b). Screening and evaluation of rice false smut resistant sources. Southwest China J of Agri Sci, 25(1), 144-148.

Huang, R., Li, X., Hua, J., Ma, H., Qiu, Z., Liang, Y., \& Lan, B. (2010). Studies on resistance to rice false smut in hybrid rice varieties (combinations). Acta Agriculturae Universitatis Jiangxiensis, 32(4), 718-720.

Huang, S., \& Yu, L. (2002). Present situation of studies on rice false smut (Ustilaginoideavirens) in China. Acta Agriculturae Jiangxi, 14(2), 45-51.

Ikegami, H. (1962). Study on the false smut of rice V. Seedling inoculation with the chlamydospores of the false smut fungus. Annals of the Phytopathological Society of Japan, 27(1), 16-23. https://doi.org/10.3186/ jjphytopath.27.16

Ikegami, H. (1963). Studies on the false smut of rice. X. Invasion of chlamydospores and hyphae of the false smut fungus into rice plants. Research Bull of the Faculty of Agri, Gifu Univ, 18, 54-60.

Jiang, S. (2010). Resistance evaluation of 34 rice varieties against false smut and the biochemical substances of rice to false smut (Phytopathological Master Thesis, Hainan University, China).

Jiang, S., Tang, C., \& Tan, Z. (2010a). Advances on studies about false smut of rice. Chinese J of Tropical Agri, 30(3), 62-66.

Jiang, S., Tang, C., \& Tan, Z. (2010b). Field resistance evaluation of 35 rice varieties against false smut. Chinese J of Tropical Crops, 31(5), 849-851.

Jin, S., Dai, G., He, R., Qian, D., \& Xue, H. (2005). Resistance evaluation of 11 rice (Oryzasativa) varieties to Ustilaginoidea virens. J of Shanghai Jiaotong Univ (Agri Sci), 23(3), 317-320.

Li, X., Liu, E., Tan, X., Xiao, Q., Liu, N., \& Wang, J. (2010). Activities of three defensive enzymes in rice resistant to the false smut. Plant Protection, 36(1), 91-94.

Li, Y., Huang, S., Yang, J., \& Wang, C. (2011). Analysis of quantitative trait loci for resistance to rice false smut. Acta Agronomica Sinica, 37(5), 778-783. https://doi.org/10.3724/SP.J.1006.2011.00788

Li, Y., Kang, B. J., Zhang, B. D., Lan, Y. T., Zeng, H. L., Ma, H. K., ... Li, T. F. (1986). Primary studies on rice false smut. Guangdong Agri Sci, 4, 45-47.

Li, Y., Zhu, Z., Zhang, Y., Zhao, L., \& Wang, C. (2008). Genetic analysis of rice false smut resistance using major gene plus polygene mixed genetic model. Acta Agronomica Sinica, 34(10), 1728-1733. https://doi.org/10.1016/S1875-2780(09)60007-9

Liao, Q. (1992). Studies on infection route of rice false smut. J of Yunnan Agri Univ, 7(1), 40-42.

Liao, Q. (1993). Studies on evaluationtechnique for thevarietal resistance to seed-borne rice false smut. $J$ of Yunnan Agri Univ, 8(3), 209-212.

Liao, Q. (1994). Studies on the sclerotium of Ustilaginoidea virens (Cooke) Tak. J of Yunnan Agri Univ, 9(2), 101-104.

Liu, B., Chen, S., Dong, D., Qian, L., \& Xu, Z. (2009a). Study on the relationship between rice plant type and false smut of rice. Hubei Agri Sci, 48(1), 42-46.

Liu, C., Chen, Z., \& Zhang, G. (2007). First exploration of invasion period and its pathogenic factor of rice false smut (Ustilaginoidea virens). Modern Agri Sci and Tech (Plant Protection), 21, 68-70

Liu, J., Tang, T., Zhang, S., \& Zheng, H. (2009b). Preliminary studies on initial infection sources and pathogen-infecting favorable stage for rice false smut. Hybrid Rice, 24(1), 74-77.

Liu, Y., Lu, F., Chen, Z., Li, Y., \& Yu, Y. (2000). Resistance to rice false smut (Ustilaginoidea virens) of main cultivars and reserve varieties in Jiangsu provice. Crops, 6, 11-13. 
Lore, J. S., Pannu, P. P. S., Jain, J., Hunjan, M. S., Kaur, R., \& Mangat, G. S. (2013). Susceptibility of rice hybrids and inbred cultivars to false smut under field conditions. Indian Phytopathology, 66(4), 397-399.

Lu, D., Mao, J., Wang, P., He, Z., \& Chen, F. (2008). Resistant difference of indica rice hybrid varieties to rice false smut. Acta Phytopathologica Sinica, 35(4), 289-294.

Lu, H., Li, C., \& Yang, J. (2006). Simple analysis of epidemic reasons for rice false smut (Ustilaginoidea virens) in Zhenba county Shannxi province in 2005. Shannxi Agri Sci, 76(2), 106.

Lu, J. (2013). Preliminary studies on the interaction between Ustilaginoidea virens and rice (Phytopathological Master Thesis, Huazhong Agri Univ., China).

Lv, Y., Lv, Y., Teng, Z., Lv, H., Chen, D., Zhang, A., ... Li, J. (2007). First exploration of occurrence reasons and control methods for japonica rice false smut (Ustilaginoidea virens). Shanghai Agri Sci \& Tech, 2, 105-106.

Mandhare, V. K., Gawade, S. B., Game, B. C., \& Padule, D. N. (2008). Prevalence and incidence of bunt and false smut in paddy (Oryza sativa L.) seeds in Maharastra. Agri Sci Digest, 28, 292-294.

Miao, Q. M. (1992). Studies on infection route of rice false smut. J of Yunnan Agri Univ, 7, 40-2.

Ou, S. H. (1985). False Smut (Green Smut). In S. H. Ou (Ed.), Rice disease (2nd ed., pp. 307-311). Commonwealth Mycology Institute, Famham Royal, UK.

Pan, B., Yang, C., Yang, Z., Li, C., Zhu, X., Yang, J., ... Tan, X. (2012). Resistant reactions of different rice varieties (lines) to different sources of rice false smut strain. Hunan Agri Sci, 9, 71-73.

Pan, X., \& Li, K. (1997a). Effect of total nitrogen fertilizer, dosage of panicle fertilizer and application period of earing fertilizer on the occurrence degree of to rice false smut (Ustilaginoidea virens). Hebei Agri Reclamation Sci \& Tech, 2, 6-9.

Pan, X., Li, K., \& Zhang, S. (1997b). Studies on the relationship between occurrence degree of rice false smut (Ustilaginoidea virens) and meteorological factors. Hebei Agri Reclamation Sci \& Tech, 2, 9-12.

Pan, X., Zhang, S., Gao, J., \& Zhang, X. (1993). Effect of nitrogen and phosphatic fertilizer on the occurrence degree of rice false smut (Ustilaginoidea virens). Hebei Agri Sci, 1, 18-20.

Phatak, R. K., \& Sachan, S. N. (1991). Occurrence of false smut on rice in Doon-Valley. Advances in Plant Sciences, 4(2), 414-415.

Qian, J., Yan, W., \& Wu, W. (1993). Relationship of rice false smut (Ustilaginoidea virens) occurrence and illumination intensity. Yunnan Agri Sci \& Tech, 2, 16-17.

Qing, T., Zhang, Z., Zhang, C., \& Chai, R. (2014). Effect of fertilization level of nitrogen phosphorus and potassium on the damage of rice false smut (Ustilaginoidea virens). Zhejiang Agri Sci, 2, 225-226.

Schroud, P., \& TeBeest, D. O. (2005). Germination and infection of rice roots by spores of Ustilaginoidea virens. In R. J. Norman, J. F. Meullenet, \& K. A. K. Moldenhauer (Eds.), Arkansas Agricultural Experiment Station Research Series (Vol. 540, pp. 143-151).

Singh, G. P., Singh, R. N., \& Singh, R. A. (1987). Status of false smut (FS) of rice in eastern Uttar Pardesh, India. International Rice Research Newsletter, 12(2), 28.

Singh, R. A., Verma, R. K., \& Pant, G. B. (1981). Studies on Claviceps oryzae sativae, the incitant of false smut of rice. International Rice Research Newsletter, 6(2), 10.

Sonoda, R., Ashizawa, T., Koga, H., \& Saito, H. (1997). Estimation of infection period of rice false smut (Ustilaginoidea virens) in the field. Annual Report of the Society of Plant Protection of North Japan, 48, 39-42.

Tang, S., Gao, D., Chen, Y., \& Li, Y. (2012a). Study on the false smut resistance of new rice combinations (lines) from the middle and lower Yangtze River and Hunan regional trials. Journal of Agriculture, 2(8), 28-32.

Tang, Y. X., Jin, J., Hu, D. W., Yong, M. L., Xu, Y., \& He, L. P. (2012b). Elucidation of the infection process of Ustilaginoidea virens (teleomorph: Villosiclava virens) in rice spikelets. Plant Pathology, 62(1), 1-8.

TeBeest, D. O. (2010). Infection of rice by Ustilaginoidea viren. Phytopathology, 100(6, Supp1. 1), S125.

Urmila, D., Dhua, S. R., \& Dhua, U. (1999). Evaluation of rice germplasm against false smut disease of rice. Oryzae, 369(2), 190-191.

Wang, D., Wang, S., Fu, J. (2004). Research advance on false smut of rice. Liaoning Agri Sci, 1, 21-4. 
Wang, G. (1992). Studies on the infection period and the infection gate of the chlamydospores of Ustilaginoidea virens (Cooke) Tak on rice. Acta Phytopathologica Sinica, 19(2), 97-100.

Wang, H., \& Lin, F. (2008). Research progress of rice false smut (Ustilaginoidea virens). Acta Agriculturae Zhejiangensis, 20(5), 385-390.

Wang, J., \& Chen, Y. (2005b). Investigation of epidemiology of rice false smut in middle and late rice in 2004 in Hunan province. China Plant Protection, 25(8), 14-15.

Wang, L., Shi, J., Li, D., Zhang, Q., Li, X., Luo, Y., ... Huang, F. (2013). Studies on rice false smut resistance of Yixiang hybrid varieties. J of Sichuan Agri Univ, 31(4), 365-369.

Wang, S., Pan, Y., Fan, J., Liu, X., Yang, H., Dong, H., \& Zhou, Y. (2005a). PCR testing of rice false smut pathogen (Ustilaginoidea virens) on rice plants at reproductive stage. Liaoning Agri Sci, 5, 46-47.

Wang, S., Qin, S., Liu, M., Li, Y., Dong, H., \& Sun, B. (2010). Effects of different cultivation modes on the occurrence degree of the rice false smut. Plant Protection, 36(6), 165-167.

Xu, C., \& Xie, G. (2001). Research status of rice false smut (Ustilaginoidea virens) at home and abroad. Seed, 6, 31-33.

Xu, J., Xue, Q., Luo, L., \& Li, Z. (2002). Preliminary report on quantitative trait loci mapping of false smut resistance using near-isogenic introgression lines in rice. Acta Agriculturae Zhejiangensis, 14(1), 14-19.

Xu, Z., Chen, W., \& Zhang, L. (1987). Correlation of rice false smut occurrence with some characteristic of rice plant type. Liaoning Agri Sci, 4, 5-8.

Yang, C., Li, L., Feng, A., Zhu, X., \& Li, J. (2014). Transcriptional profiling of the responses to infection by the false smut fungus Ustilaginoidea virens in resistant and susceptible rice varieties. Canadian $J$ of Plant Pathol, 36(3), 377-388.

Yang, J., Liu, X., \& Ding, G. (2008). Preliminary study on resistance to rice false smut from different rice varieties. Seed, 27(9), 106-107.

Yang, X. (2007). Occurrence condition, forecasting and management of rice false smut in southeast of Guizhou Province. Guizhou Agri Sci, 35(1), 100-101.

Yao, L., Ye, H., Hu, R., Wu, J., Lu, D., Mao, J., \& He, Z. (2012). Preliminary research on infection mechanism of rice false smur (Ustilaginoidea virens). Southwest China J of Agri Sci, 25(4), 1273-1276.

Yashoda, H., \& Anahosur, K. H. (2000). Influence of weather parameters on the incidence of false smut of rice. Advances in Agri Res in India, 14, 161-165.

Ye, H., Chen, G., Cheng, N., Fang, R., Ke, M., \& Leng, S. (2005). First exploration of rice false smut epidemic and weather conditions. Hubei Plant Protection, 2, 37-38.

Zhang, J., Chen, Z., Zhang, B., Liu, Y., \& Lu, F. (2004). Inoculation techniques used for inducing Rice false smut efficiently. Acta Phytopathologica Sinica, 34(5), 463-467.

Zhang, P., \& Jin, G. (1997). Research progress of rice false smut (Ustilaginoidea virens) in Heilongjiang province. Heilongjiang Agri Sci, 2, 48-51.

Zhang, S., Chen, Q., Lv, L., Yang, X., \& Yu, D. (2006). Identification of partial main cultivars' resistance to rice false smut (Ustilaginoidea virens) in Hubei province. Anhui Agri Sci Bull, 12(5), 76-78.

Zhao, X. (2008). The occurrence reasons of rice false smut and its management strategies. Modern Agri Sci and Tech, 12, 157.

Zheng, Y., Zhu, Y., Su, D., Wang, Y., Lian, L., ... Xie, H. (2013). Evaluation on Primal Parental Varieties Resistance to Rice False Smut for Rice Breeding. Fujian J of Agri Sci, 28(10), 1021-1026.

Zhou, Y. L., Izumitsu, K., Sonoda, R., Nakazaki, T., Tanaka, E., Tsuda, M., \& Tanaka, C. (2003). PCR-based specific detection of Ustilaginoidea virens and Ephelis japonica. J of Phytopathol, 151(9), 513-518.

Zhou, Y. L., Xie, X. W., Zhang, F., Wang, S., Liu, X. Z., Zhu, L. H., ... Li, Z. K. (2014). Detection of quantitative resistance loci associated with resistance to rice false smut (Ustilaginoidea virens) using introgression lines. Plant Pathol, 63(2), 365-372.

Zhou, Y., Xie, X., Wang, S., Pan, Y., Liu, X., Yang, H., ... Li, Z. (2006). Detection of Ustilaginoidea virens from rice field and plants by nested PCR. J of Agri Biotechnol, 14(4), 542-545. 
Zhou, Y., Xu, J., Xie, X., Gao, X., Wang, J., \& Li, Z. (2010). Effects of maturity group of cultivar, pathogen amount and sowing date on the severity of rice false rice false smut in the field. Acta Phytopathologica Sinica, 37(2), 97-103.

Zuo, G., Ran, X., Du, S., Zhang, S., \& Tian, S. (1996). Studies on original source of infection of rice false smut. Chinese Agri Sci Bull, 12(5), 17.

\section{Copyrights}

Copyright for this article is retained by the author(s), with first publication rights granted to the journal.

This is an open-access article distributed under the terms and conditions of the Creative Commons Attribution license (http://creativecommons.org/licenses/by/4.0/). 